\title{
AN EMPIRICAL-BASED APPROACH FOR MODELING AND ASSESSMENT OF RC COLUMNS WITH PLAIN BARS
}

\author{
Gerardo M. Verderame ${ }^{1}$ and Paolo Ricci ${ }^{1}$ \\ ${ }^{1}$ University of Naples Federico II, Department of Structures for Engineering and Architecture \\ Via Claudio 21 - 80125 - Naples - Italy \\ e-mail: \{verderam,paolo.ricci\}@unina.it
}

Keywords: reinforced concrete columns, assessment, plain bars, lumped plasticity, empiricalbased, macromodel.

\begin{abstract}
There is a growing need for numerical models simulating the non-linear behavior of Reinforced Concrete (RC) elements under seismic loads into inelastic range, and for capacity models assessing the deformation capacity of $R C$ members, with emphasis on non-conforming existing buildings. As far as nonlinear modeling is concerned, several approaches have been proposed by different authors; among them, empirical-based macromodels for lumped plasticity modeling (e.g. Haselton et al., 2008) can represent an effective compromise between accuracy and simplicity. They have the great advantage of providing a complete characterization of the nonlinear response, accounting for all of the deformation mechanisms, and their reliability is based on the use of experimental data. They also allow evaluating error/dispersion measures of the simulated response compared to the experimental data they are based on, which can be suitably used for taking into account modeling uncertainties in seismic fragility analyses of RC frames. With regard to capacity models, different approaches have been proposed for the assessment of the deformation capacity of $R C$ members, also for pre-normative purposes; in particular, as far as the seismic assessment of existing RC buildings is concerned, different capacity models have been developed for the ultimate deformation capacity of nonconforming elements subjected to different failure modes (e.g. Elwood and Moehle, 2005; Zhu et al., 2007).
\end{abstract}

In this study, a nonlinear response macromodel is proposed for a specific type of member, i.e. $R C$ columns with plain bars. To this end, a database of tests on RC columns with plain bars is collected from literature. The specimens have different axial load, material properties, geometry, and longitudinal and transverse reinforcement ratio. Force-displacement data are collected and processed for each specimen. The backbone of the experimental response is evaluated for each test, and predictive equations are developed for characteristics points, namely yielding, maximum strength, ultimate (conventional collapse) and zero resistance conditions, based on a statistical analysis of data. 


\section{INTRODUCTION}

Current models for assessment and nonlinear modeling of RC elements are usually based on members with deformed bars (e.g. [1], [2], [3]). The post-elastic response of members with plain bars can be significantly different compared to members with deformed bars, due to the lower bond capacities [4][5] that, for instance, lead to higher deformability contribution of the fixed-end-rotation mechanism [6][7]. The objective of this paper is the derivation of empirical expressions providing the expected post-elastic response backbone for this kind of elements, through a regression analysis carried out on collected experimental data.

In literature, one of the most widespread empirical macromodels for predicting the nonlinear response of RC members has been proposed by Haselton et al. [8], which provide a trilinear response backbone and a parameter for modeling the stiffness/strength degradation, according to the cyclic response model proposed by Ibarra et al. [9]. The largest part of models for capacity assessment and modeling of RC members provides the prediction of the response already including the degradation due to cyclic displacement, as in the present study. Among these, the studies by Fardis and co-workers, which have proposed empirical-based formulations for chord rotation at yielding and "ultimate" (at 20\% strength drop) [10][11][2], based on a large database of flexure-controlled experimental tests on RC elements. In the last years, several studies by Elwood and co-workers are focusing on the deformation capacity of existing non-ductile RC elements. Elwood and Moehle [12][13] proposed empirical formulations providing the drift at "collapse" (20\% strength drop) and at "axial failure" (loss of vertical load-carrying capacity) of RC columns failing in shear following flexural yielding. These drift limits were used to model the shear-controlled response of RC elements (subjected to flexure-shear failure mode) in [14], by means of a modeling approach based on the use of the "limit state" material in OpenSees [15]. Aslani and Miranda [16] re-evaluated and simplified the formulations by Elwood and Moehle [12][13]. Zhu et al. [17] proposed a procedure for failure mode classification and, accordingly, empirical formulations for the prediction of drift capacity (at 20\% strength drop) for columns failing in flexure or in shear/flexure-shear, and for the prediction of the drift capacity at axial failure of shear-controlled columns.

Different approaches have been adopted by international codes. The European standard EC8 adopted Fardis and co-workers' proposals, including correction coefficients for ultimate chord rotation of non-conforming elements [18][19], which account for their lower deformation capacity [20][2]. The US standard ASCE/SEI 41-13 [21] provides a procedure for the failure mode classification and, accordingly, empirical deformation capacity parameters calibrated to satisfy a target failure probability, depending on the failure mode. Such provisions were based on a proposal by Elwood et al. [1]. In [22] and [3] a modification to ASCE/SEI 41 provisions was proposed, in particular consisting of empirical expressions - not dependent on the expected failure mode - providing a median estimate of deformation capacity parameters.

A much lower amount of analytical studies regarding the assessment of the deformation capacity of RC members with plain bars is present in literature. The European standard EC8 provides specific expressions of the above-mentioned correction coefficients EC8 [18][19] for this kind of elements. These coefficients, in particular, account for the reduction of the ultimate chord rotation as a function of limited lap splice length. Different authors have evaluated the effectiveness of these coefficients, in some cases proposing improvements or alternative expressions [1][23][24]. Moreover, the effectiveness of current ASCE/SEI 41 provisions for elements with plain bars has been evaluated in [25], highlighting a significant conservatism.

In this study, an empirical macromodel is developed, providing the response envelope of flexure-controlled RC columns with plain bars. To this aim, a database of cyclic tests from 
literature is collected, and empirical formulations are proposed to evaluate the characteristic points of the response.

\section{EXPERIMENTAL DATABASE}

In this Section, the experimental database used for the empirical study reported in this paper is illustrated.

Cyclic experimental tests on ductile (flexure-controlled) RC columns with plain bars were collected. All the experimental responses were corrected accounting for P-Delta effects, if necessary, in order to be consistent with "Case I" reported in [26].

Table 1 reports the geometrical and mechanical characteristics of the 44 collected tests. 13 of them have overlapped longitudinal reinforcement, with a ratio between splice length and longitudinal bar diameter $15 \leq 1_{\mathrm{o}} / \mathrm{d}_{\mathrm{b}} \leq 47$.

The following parameters were extracted from the envelope of the experimental responses of the tests collected in the database. The obtained data are reported in Table 2.

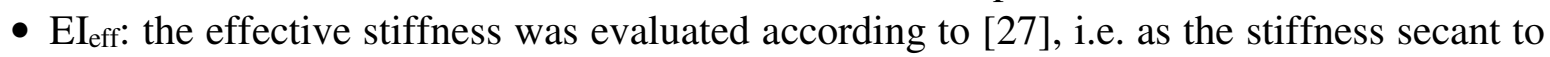
first yielding condition at theoretical first yielding moment, $M_{y}$; the ratio between $\mathrm{EI}_{\mathrm{eff}}$ and the gross section stiffness, $\mathrm{EI}_{\mathrm{g}}$, was calculated (as the average between the two loading directions; if no cyclic displacement was imposed to the specimen prior to the attainment of the yielding condition, $\mathrm{EI}_{\mathrm{eff}}$ was not calculated;

- $\mathrm{M}_{\max }$ : the peak resistance was evaluated only if cyclic displacement was imposed to the specimen prior to the attainment of this condition; again, the average between the two loading directions was calculated;

- $\theta_{\max }$ : if $\mathbf{M}_{\max }$ was evaluated, chord rotation at peak resistance was considered, too;

- $\theta_{\text {ult: }}$ chord rotation at "ultimate" was evaluated corresponding to a $20 \%$ strength drop on the envelope of the response curve [10][13]; if $0.80 \cdot \mathrm{M}_{\max }$ was not reached in the softening response, the corresponding value was not reported; for this parameter, the lowest value between the two loading directions was considered;

- $\theta_{0}$ : chord rotation at zero resistance was evaluated extrapolating to zero the line interpolating the extreme envelope points of the softening branch of the response; again, the lowest value between the two loading directions was considered;

- $\mathrm{K}_{0}$ : softening stiffness toward zero resistance was identified with the slope of the abovedescribed interpolating line used to evaluate $\theta_{0}$.

An example application of the illustrated procedures is shown in Figure 1. 


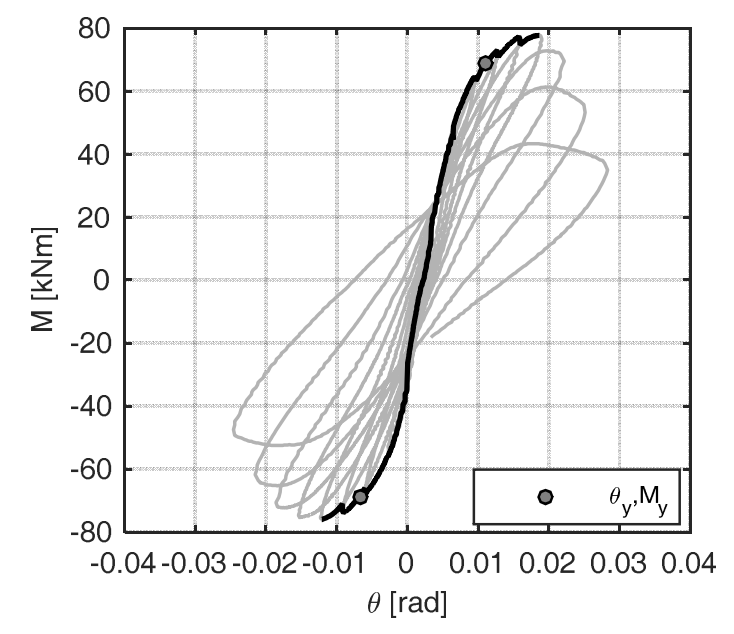

(a)

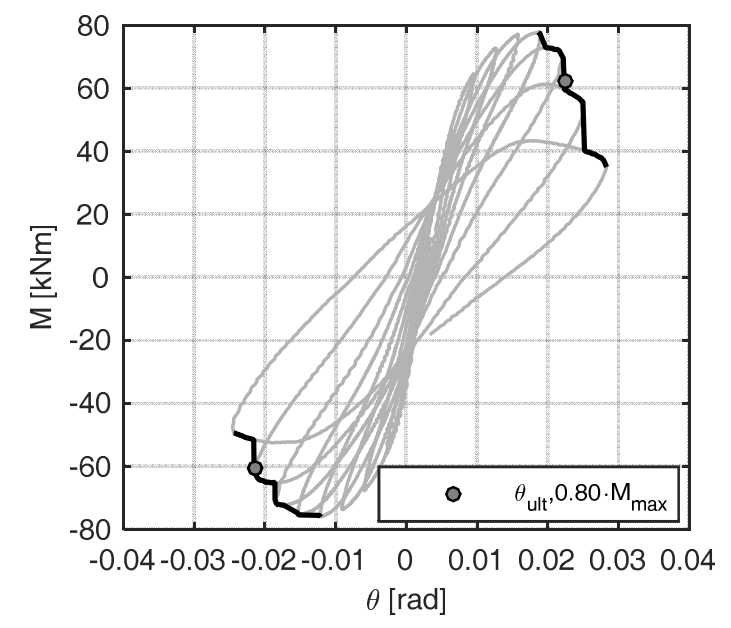

(c)

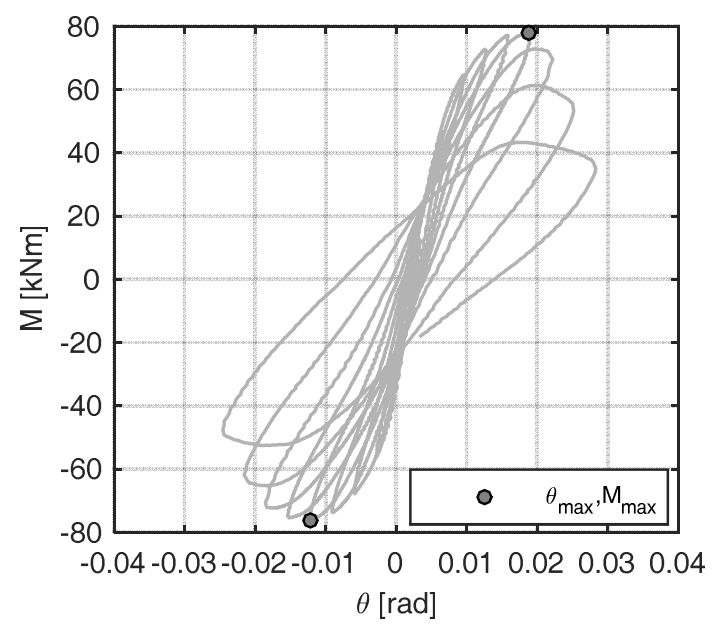

(b)

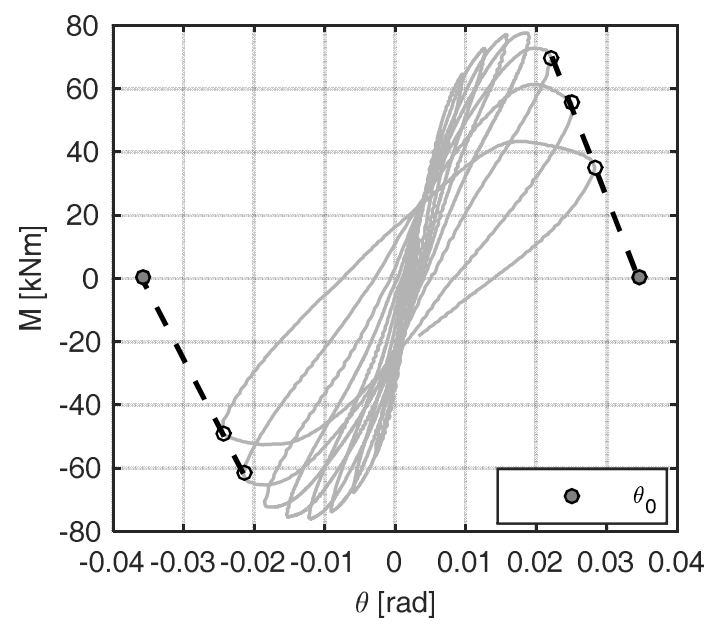

(d)

Figure 1: Example data extraction for Specimen Q-0L1 from [28] at yielding (a), peak resistance (b), "ultimate" (c), and zero resistance (d) conditions 


\begin{tabular}{|c|c|c|c|c|c|c|c|c|c|c|c|c|c|c|}
\hline \# & Reference & Specimen & $\begin{array}{c}v \\
{[-]}\end{array}$ & $\begin{array}{c}\mathbf{b} \\
{[\mathrm{mm}]}\end{array}$ & $\begin{array}{c}\mathbf{h} \\
{[\mathrm{mm}]}\end{array}$ & $\begin{array}{c}\mathbf{d} \\
{[\mathrm{mm}]}\end{array}$ & $\begin{array}{c}\mathbf{L}_{\mathrm{s}} \\
{[\mathrm{mm}]}\end{array}$ & $\begin{array}{c}\mathbf{s} \\
{[\mathrm{mm}]}\end{array}$ & $\begin{array}{c}\mathbf{f}_{\mathrm{c}} \\
{[\mathrm{MPa}]}\end{array}$ & $\begin{array}{c}\mathbf{f}_{\mathbf{y}} \\
{[\mathrm{MPa}]}\end{array}$ & $\begin{array}{c}\mathbf{f}_{\mathrm{yw}} \\
{[\mathrm{MPa}]}\end{array}$ & $\begin{array}{c}\mathbf{d}_{\mathbf{b}} \\
{[\mathbf{m m}]}\end{array}$ & $\begin{array}{l}\rho_{1} \\
{[-]}\end{array}$ & $\begin{array}{l}\omega_{1} \\
{[-]}\end{array}$ \\
\hline 1 & \multirow{7}{*}{ [6] } & C270-A1 & 0.12 & 300 & 300 & 270 & 1570 & 100 & 25 & 355 & 430 & 12 & 0.008 & 0.12 \\
\hline 2 & & $\mathrm{C} 270-\mathrm{A} 2$ & 0.12 & 300 & 300 & 270 & 1570 & 100 & 25 & 355 & 430 & 12 & 0.008 & 0.12 \\
\hline 3 & & C270-B1 & 0.12 & 300 & 300 & 270 & 1570 & 100 & 25 & 355 & 430 & 12 & 0.008 & 0.12 \\
\hline 4 & & C540-A1 & 0.24 & 300 & 300 & 270 & 1570 & 100 & 25 & 355 & 430 & 12 & 0.008 & 0.12 \\
\hline 5 & & C540-B1 & 0.24 & 300 & 300 & 270 & 1570 & 100 & 25 & 355 & 430 & 12 & 0.008 & 0.12 \\
\hline 6 & & C540-B2 & 0.24 & 300 & 300 & 270 & 1570 & 100 & 25 & 355 & 430 & 12 & 0.008 & 0.12 \\
\hline 7 & & S300P-c & 0.20 & 300 & 300 & 270 & 1500 & 150 & 17.9 & 330 & 375 & 12 & 0.011 & 0.21 \\
\hline 8 & \multirow[t]{2}{*}{ [29] } & R300P-c & 0.10 & 500 & 300 & 270 & 1500 & 150 & 19.2 & 330 & 375 & 12 & 0.010 & 0.17 \\
\hline 9 & & R500P-c & 0.10 & 300 & 500 & 470 & 1500 & 150 & 20.2 & 330 & 375 & 12 & 0.010 & 0.16 \\
\hline 10 & \multirow{2}{*}{ [30] } & G5 & 0.20 & 300 & 300 & 270 & 1500 & 300 & 21.6 & 330 & 375 & 12 & 0.011 & 0.17 \\
\hline 11 & & C-R30-s & 0.20 & 500 & 300 & 270 & 1500 & 150 & 19.2 & 330 & 375 & 12 & 0.010 & 0.17 \\
\hline 12 & \multirow{5}{*}{ [28] } & Q-0 & 0.44 & 250 & 250 & 210 & 1600 & 200 & 27 & 313 & 425 & 14 & 0.012 & 0.14 \\
\hline 13 & & Q-0L1 & 0.41 & 250 & 250 & 220 & 1600 & 200 & 30.3 & 313 & 425 & 14 & 0.011 & 0.12 \\
\hline 14 & & Q-0L2 & 0.42 & 250 & 250 & 220 & 1600 & 200 & 30.3 & 313 & 425 & 14 & 0.011 & 0.12 \\
\hline 15 & & Q-0L1a & 0.63 & 250 & 250 & 220 & 1600 & 200 & 28.1 & 313 & 425 & 14 & 0.011 & 0.12 \\
\hline 16 & & Q-0L2a & 0.57 & 250 & 250 & 220 & 1600 & 200 & 28.1 & 313 & 425 & 14 & 0.011 & 0.12 \\
\hline 17 & [31] & $\mathrm{C}$ & 0.30 & 250 & 250 & 215 & 1600 & 200 & 25 & 372 & 351 & 14 & 0.011 & 0.17 \\
\hline 18 & [32] & Control & 0.20 & 250 & 250 & 215 & 1600 & 200 & 25.6 & 372 & 351 & 14 & 0.011 & 0.17 \\
\hline 19 & [33] & $\mathrm{C}-\mathrm{O}-1$ & 0.47 & 200 & 300 & 265 & 1200 & 200 & 9.0 & 336 & 383 & 14 & 0.012 & 0.43 \\
\hline 20 & \multirow{3}{*}{ [34] } & $\mathrm{C}_{3}^{3}$ & 0.14 & 300 & 300 & 270 & 1700 & 200 & 25.7 & 346 & 346 & 14 & 0.008 & 0.10 \\
\hline 21 & & C16-S & 0.40 & 300 & 300 & 270 & 1700 & 200 & 27.5 & 346 & 346 & 14 & 0.008 & 0.10 \\
\hline 22 & & C18-S & 0.40 & 300 & 300 & 270 & 1700 & 200 & 13.5 & 346 & 346 & 14 & 0.008 & 0.19 \\
\hline 23 & [35] & $\mathrm{CC} 2 \mathrm{~N}$ & 0.20 & 200 & 200 & 185 & 750 & 100 & 23 & 356 & 356 & $10 / 6$ & 0.012 & 0.18 \\
\hline 24 & \multirow{3}{*}{ [36] } & WOS-C & 0.15 & 250 & 250 & 220 & 750 & 200 & 22.9 & 370 & 370 & 12 & 0.008 & 0.13 \\
\hline 25 & & HOS-C & 0.15 & 250 & 250 & 220 & 750 & 200 & 24.8 & 370 & 370 & 12 & 0.008 & 0.12 \\
\hline 26 & & S-L-0-00 & 0.40 & 350 & 350 & 302 & 2000 & 200 & 14 & 275 & 331 & 18 & 0.019 & 0.38 \\
\hline 27 & \multirow[t]{5}{*}[37]{$[38][39]$} & S-H-0-00 & 0.32 & 350 & 350 & 302 & 2000 & 200 & 20 & 284 & 331 & 22 & 0.029 & 0.41 \\
\hline 28 & & R-NC-0-00 & 0.50 & 200 & 400 & 350 & 2000 & 200 & 12 & 275 & 331 & 18 & 0.029 & 0.67 \\
\hline 29 & & $1 \mathrm{P} 2$ & 0.21 & 350 & 350 & 315 & 2000 & 165 & 13.5 & 315 & 368 & 14 & 0.011 & 0.26 \\
\hline 30 & & $2 \mathrm{P} 3$ & 0.20 & 350 & 350 & 315 & 2000 & 165 & 12.2 & 315 & 368 & 14 & 0.011 & 0.29 \\
\hline 31 & & 3P3_N0.4 & 0.40 & 350 & 350 & 315 & 2000 & 165 & 13.1 & 315 & 368 & 14 & 0.011 & 0.27 \\
\hline 32 & \multirow[t]{7}{*}[40]{$[41][42]$} & $4 \mathrm{P} 4$ & 0.20 & 350 & 350 & 315 & 2000 & 165 & 12.4 & 315 & 368 & 14 & 0.011 & 0.28 \\
\hline 33 & & & 0.21 & 350 & 350 & 315 & 2000 & 165 & 11.4 & 315 & 368 & 14 & 0.011 & 0.31 \\
\hline 34 & & 11 & 0.20 & 350 & 350 & 315 & 2000 & 16 & 12.5 & 315 & 368 & 14 & 0.011 & 0.28 \\
\hline 35 & & 7P3_U & 0.20 & 350 & 350 & 315 & 2000 & 165 & 13.2 & 315 & 368 & 14 & 0.011 & 0.27 \\
\hline 36 & & CPA-1 & 0.18 & 300 & 300 & 270 & 1700 & 200 & 21.2 & 405 & 410 & 12 & 0.008 & 0.16 \\
\hline 37 & & CPA-3 & 0.18 & 300 & 300 & 270 & 1700 & 200 & 17.4 & 405 & 410 & 12 & 0.008 & 0.19 \\
\hline 38 & & $\mathrm{CPB}$ & 0.18 & 300 & 300 & 270 & 1700 & 200 & 20.3 & 405 & 410 & 12 & 0.008 & 0.17 \\
\hline 39 & \multirow[t]{4}{*}{ [24] } & CPC & 0.18 & 300 & 300 & 270 & 1700 & 200 & 17.1 & 405 & 410 & 12 & 0.011 & 0.26 \\
\hline 40 & & CPD & 0.18 & 300 & 300 & 270 & 1700 & 200 & 18 & 405 & 410 & 12 & 0.011 & 0.25 \\
\hline 41 & & $\mathrm{CPE}$ & 0.18 & 300 & 400 & 370 & 1700 & 200 & 18 & 405 & 410 & 12 & 0.008 & 0.18 \\
\hline 42 & & $\mathrm{CPF}$ & 0.18 & 300 & 500 & 470 & 1700 & 200 & 18.3 & 405 & 410 & 12 & 0.008 & 0.18 \\
\hline 43 & \multirow{2}{*}{ [43] } & S1 & 0.20 & 350 & 350 & 311 & 1425 & 265 & 29.5 & 325 & 350 & 20 & 0.023 & 0.25 \\
\hline 44 & & S4 & 0.20 & 350 & 350 & 311 & 1425 & 265 & 25.9 & 325 & 350 & 20 & 0.023 & 0.29 \\
\hline
\end{tabular}

Table 1: Database of cyclic tests on flexure-controlled RC columns with plain bars. 


\begin{tabular}{|c|c|c|c|c|c|c|}
\hline \# & $\begin{array}{c}\mathbf{E I}_{\text {eff }} / \mathbf{E} \mathbf{I}_{\mathbf{g}} \\
{[-]}\end{array}$ & $\begin{array}{c}\theta_{\max } \\
{[\mathrm{rad}]}\end{array}$ & $\begin{array}{c}\mathbf{M}_{\max } \\
{[\mathrm{kNm}]}\end{array}$ & $\begin{array}{c}\theta_{\text {ult }} \\
{[\mathrm{rad}]}\end{array}$ & $\begin{array}{c}\theta_{0} \\
{[\mathbf{r a d}]}\end{array}$ & $\begin{array}{c}\mathbf{K}_{\mathbf{0}} \\
{[\mathrm{kNm} / \mathrm{rad}]}\end{array}$ \\
\hline 1 & 0.34 & 0.015 & 66.3 & 0.062 & 0.260 & 272 \\
\hline 2 & 0.38 & 0.020 & 68.4 & 0.058 & 0.237 & 303 \\
\hline 3 & 0.38 & 0.013 & 63.2 & 0.063 & 0.147 & 602 \\
\hline 4 & 0.38 & 0.018 & 98.9 & 0.037 & 0.132 & 933 \\
\hline 5 & 0.42 & 0.017 & 96.4 & 0.038 & 0.142 & 810 \\
\hline 6 & 0.48 & 0.013 & 101.5 & 0.032 & 0.111 & 1065 \\
\hline 7 & 0.26 & 0.022 & 79.7 & 0.056 & 0.093 & 1712 \\
\hline 8 & 0.21 & 0.026 & 100.9 & 0.068 & 0.127 & 1358 \\
\hline 9 & 0.20 & 0.020 & 177.9 & - & 0.275 & 698 \\
\hline 10 & 0.34 & 0.018 & 91.5 & 0.052 & 0.192 & 565 \\
\hline 11 & 0.32 & 0.020 & 140.5 & 0.048 & 0.088 & 2736 \\
\hline 12 & 0.55 & 0.015 & 72.4 & 0.019 & 0.030 & 6664 \\
\hline 13 & 0.52 & 0.015 & 76.9 & 0.022 & 0.035 & 5657 \\
\hline 14 & 0.78 & 0.011 & 83.5 & 0.013 & 0.021 & 14050 \\
\hline 15 & 0.86 & 0.009 & 75.9 & 0.011 & 0.020 & 7238 \\
\hline 16 & 0.87 & 0.011 & 83.0 & 0.013 & 0.021 & 13952 \\
\hline 17 & 0.28 & 0.025 & 62.1 & 0.037 & 0.055 & 2752 \\
\hline 18 & 0.20 & 0.040 & 53.2 & 0.060 & 0.080 & 2312 \\
\hline 19 & 0.48 & 0.012 & 43.9 & 0.014 & 0.024 & 3432 \\
\hline 20 & 0.34 & 0.025 & 88.1 & 0.035 & 0.059 & 3329 \\
\hline 21 & 0.35 & 0.020 & 129.4 & 0.029 & 0.044 & 8723 \\
\hline 22 & 0.37 & 0.018 & 71.4 & 0.031 & 0.085 & 1065 \\
\hline 23 & 0.22 & 0.031 & 36.1 & 0.044 & 0.083 & 751 \\
\hline 24 & 0.18 & 0.014 & 40.5 & 0.047 & 0.171 & 277 \\
\hline 25 & 0.24 & 0.013 & 42.6 & 0.039 & 0.096 & 487 \\
\hline 26 & 0.50 & 0.017 & 145.9 & 0.029 & 0.042 & 9916 \\
\hline 27 & 0.48 & 0.022 & 191.1 & 0.040 & 0.063 & 7240 \\
\hline 28 & 0.66 & 0.009 & 113.2 & 0.020 & 0.048 & 3145 \\
\hline 29 & - & 0.028 & 102.6 & - & 0.301 & 351 \\
\hline 30 & - & 0.028 & 95.6 & - & 0.149 & 797 \\
\hline 31 & - & - & - & 0.030 & 0.062 & 2748 \\
\hline 32 & - & - & - & - & 0.226 & 470 \\
\hline 33 & - & - & - & - & - & - \\
\hline 34 & 0.38 & 0.021 & 95.6 & 0.052 & 0.149 & 776 \\
\hline 35 & 0.19 & 0.024 & 94.9 & 0.049 & 0.189 & 578 \\
\hline 36 & 0.26 & 0.019 & 71.5 & 0.034 & 0.063 & 2024 \\
\hline 37 & 0.32 & 0.024 & 65.4 & 0.045 & 0.081 & 1479 \\
\hline 38 & 0.45 & 0.017 & 62.0 & 0.043 & 0.078 & 1447 \\
\hline 39 & 0.23 & 0.025 & 83.6 & 0.048 & 0.072 & 2716 \\
\hline 40 & 0.37 & 0.017 & 65.0 & 0.041 & 0.077 & 1447 \\
\hline 41 & 0.15 & 0.028 & 118.8 & 0.041 & 0.057 & 6209 \\
\hline 42 & 0.21 & 0.018 & 202.4 & 0.035 & 0.058 & 6325 \\
\hline 43 & 0.24 & 0.016 & 192.6 & 0.024 & 0.049 & 6479 \\
\hline 44 & 0.27 & 0.016 & 168.3 & 0.022 & 0.039 & 8435 \\
\hline
\end{tabular}

Table 2: Extracted data at characteristic points of the base moment-chord rotation response envelopes (yielding, peak resistance, "ultimate", and zero resistance).

\section{METHODOLOGY}

The regression methodology adopted in this study consists of (i) the selection of potential predictive parameters, (ii) the analysis of the trends of the output (predicted) variable with the selected potential predictive parameters, (iii) the execution of regression analysis based on assumed functional forms, and (iv) the selection of the adopted formulation. This methodology is briefly illustrated as follows.

Based on previous literature studies and mechanical judgment, the following potential predictive parameters were selected: axial load ratio (v); shear span-to-depth ratio ( $\left.\mathrm{L}_{\mathrm{s}} / \mathrm{d}\right)$; transverse reinforcement spacing-to-depth ratio ( $\mathrm{s} / \mathrm{d})$; transverse reinforcement spacing-to-longitudinal bar diameter ratio $\left(\mathrm{s} / \mathrm{d}_{\mathrm{b}}\right)$; rebar buckling coefficient $\left(\mathrm{s}_{\mathrm{n}}=\left(\mathrm{s} / \mathrm{d}_{\mathrm{b}}\right) \cdot\left(\mathrm{f}_{\mathrm{y}} / 100\right)^{0.5}\right)$ (already adopted by Haselton et al. [8]); geometrical $\left(\rho_{1}\right)$ and mechanical $\left(\omega_{1}\right)$ longitudinal reinforcement ratio; geometrical $\left(\rho_{\mathrm{w}}\right)$ and mechanical $\left(\omega_{\mathrm{w}}\right)$ transverse reinforcement ratio; compression-to-tension (including web) longitudinal reinforcement ratio $\left(\omega^{\prime} / \omega\right)$; concrete compressive strength $\left(f_{c}\right)$; longitudinal steel yield strength $\left(\mathrm{f}_{\mathrm{y}}\right)$; splice length-to-longitudinal bar diameter ratio $\left(\mathrm{l}_{\mathrm{o}} / \mathrm{d}_{\mathrm{b}}\right)$. Furthermore, a "fixed-end-rotation coefficient", $\left(\mathrm{l}_{\mathrm{ba}} \cdot \mathrm{d}_{\mathrm{b}}\right) /\left(\mathrm{d} \cdot \mathrm{f}_{\mathrm{c}}{ }^{0.5}\right)$, was tentatively used, trying to account for the influence of fixed-end-rotation on deformation capacity; this coefficient should be positively correlated with elements' deformability, since the expected rigid end rotation due to the slip of the longitudinal reinforcement from the anchorage should be positively correlated 
to the anchorage length $\left(l_{b a}\right)$ and to the bar diameter $\left(d_{b}\right)$, and negatively correlated to the square root of concrete compressive strength $\left(\mathrm{f}_{\mathrm{c}}{ }^{0.5}\right.$, correlated to the bond strength) and to section effective depth (d, correlated to the "rotation arm")

Then, the correlation between each output variable and the potential predictive parameters was analyzed through visual inspection and analysis of correlation coefficients. Parameters showing an unexpected (not mechanically explainable) correlation with the output variable were excluded.

Ordinary least squares regressions were carried out between each output variable (transformed in logarithmic form) and the input variables; these were assumed, alternatively, in their natural or logarithmic form, or not present (leading to reduced models, in the latter case). The best model was selected as the one characterized by the lowest Residual Sum of Squares (RSS) among all the full models.

Finally, F-tests were performed between the best model and all the reduced models searching for statistically significant differences. If the p-value was higher than a fixed significance level $\alpha=0.10$ (assumed higher than 0.05 in order to reduce the risk of a "Type II" error [44]) the null hypothesis was not rejected, i.e. the reduced model was "accepted" as statistically equivalent to the best model. Among all the "accepted" reduced models, the one with the lowest number of predictive parameters and the highest p-value was selected. In some cases, a further parameter was included, if it led to a very significant increase in p-value. If possible, the expression was simplified in linear form. Statistics of the observed-to-predicted ratio (mean, median and Coefficient of Variation $(\mathrm{CoV})$ ) were calculated.

\section{ANALYSIS OF RESULTS}

The empirical formulations derived according to the above-described methodology are illustrated as follows for each parameter analyzed.

\section{Effective stiffness}

The regression obtained for $\mathrm{EI}_{\mathrm{eff}} / \mathrm{EI}_{\mathrm{g}}$ includes the axial load ratio and the shear span-to-depth ratio, see Eq. 1. As expected, the effective stiffness increases with these parameters increasing. The strongest correlation is observed with the axial load ratio, consistent with previous literature and code expressions and mechanical-based judgment.

$$
E I_{\text {eff }} / E I_{g}=0.086 \cdot 7.6^{v} \cdot\left(1+0.23 \cdot L_{s} / d\right)
$$

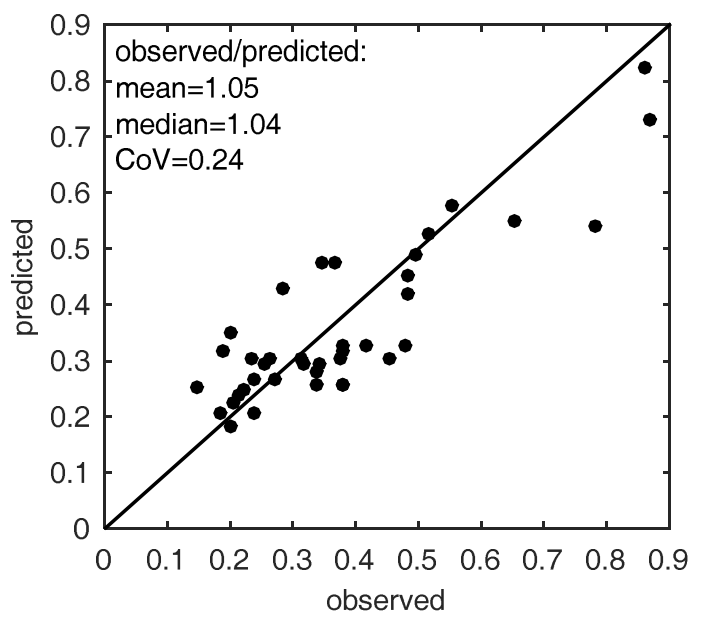

Figure 2: observed vs predicted $\mathrm{EI}_{\mathrm{eff}}$ (Eq. 1) 
Mean, median and CoV of the observed-to-predicted ratio are 1.05, 1.04 and 0.24, see Figure 2.

The observed values of $\mathrm{EI}_{\mathrm{eff}} / \mathrm{EI}_{\mathrm{g}}$ can be compared with the ASCE/SEI 41-13 provisions; mean, median and $\mathrm{CoV}$ of the observed-to-predicted ratio are $0.82,0.83$ and 0.30 , singularly equal to the values observed by Elwood and Eberhard [27] on rectangular columns with deformed bars; hence, the presence of plain bars does not seem to increase the deformability at yielding [11]. However, if a non-biased estimate of the expected stiffness has to be provided, the lower bound could be decreased from 0.30 to 0.20 ; mean, median and $\mathrm{CoV}$ of the observedto-predicted equal to 0.98, 0.94 and 0.31 would be obtained, see Figure 3.

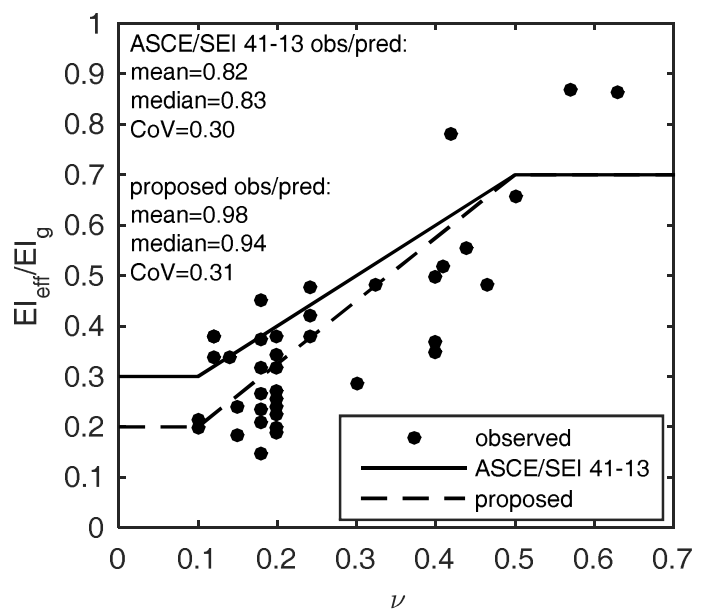

Figure 3: observed $\mathrm{EI}_{\mathrm{eff}} / \mathrm{EI}_{\mathrm{g}}, \mathrm{ASCE} / \mathrm{SEI}$ 41-13 provision and proposed modification

\section{Peak resistance}

First, an attempt of predicting the observed flexural strength $\mathbf{M}_{\max }$ through a section analysis is made, estimating the maximum expected moment as the moment calculated with a fiber analysis using a bilinear elastic-perfectly plastic model for the steel and the Mander et al. [45] constitutive relationship for the concrete, corresponding to a compressive strain of 0.004 in the extreme concrete fiber [27], $\mathrm{M}_{004}$. Mean, median and $\mathrm{CoV}$ of the ratio between $\mathrm{M}_{\max }$ and $\mathrm{M}_{004}$ are $1.08,1.06$ and 0.11 , thus highlighting an experimental overstrength that has already been observed in literature, and can be explained through the confinement effect of the foundation element on the end section of the element [46]. Therefore, a regression analysis is carried out for the $\mathrm{M}_{\max } / \mathrm{M}_{\mathrm{y}}$ ratio, but the obtained results do not show a significant scatter reduction compared to the observed values; thus, a simple mean value could be assumed for this ratio, i.e. $\mathrm{M}_{\max } / \mathrm{M}_{\mathrm{y}}=1.17$.

\section{Chord rotation at peak resistance}

The regression obtained for $\theta_{\max }$ includes the axial load ratio, the shear span-to-depth ratio and the splice length-to-longitudinal bar diameter ratio, see Eq. 2. Mean, median and CoV of the observed-to-predicted ratio are 1.00, 0.98 and 0.24, see Figure 4. A negative correlation is observed with the geometrical longitudinal reinforcement ratio, too, but it is not retained in the formulation selected according to the adopted methodology. Note the minimum between $1_{\mathrm{o}} / \mathrm{d}_{\mathrm{b}}$ and 50 was assumed in regression analysis.

$$
\theta_{\max }=0.011 \cdot 0.21^{v} \cdot\left(1+0.29 \cdot L_{s} / d\right) \cdot\left(0.57+0.43 \cdot \min \left(l_{o} / d_{b}, 50\right) / 50\right)
$$




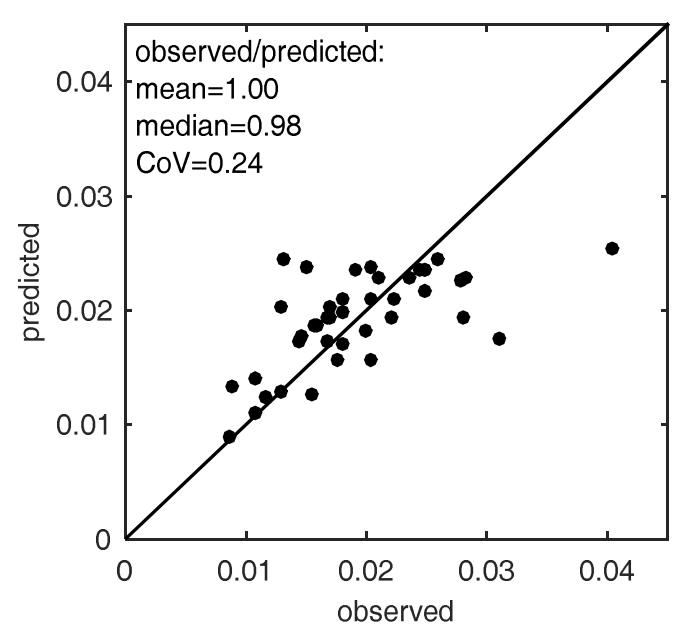

Figure 4: observed vs predicted $\theta_{\max }$ (Eq. 2)

\section{Chord rotation at "ultimate"}

The regression obtained for $\theta_{\text {ult }}$ includes the axial load ratio, the mechanical transverse reinforcement ratio, the "fixed-end-rotation coefficient" proposed in this study, and the splice length-to-longitudinal bar diameter ratio, see Eq. 3. The terms related to the two latter coefficients could be approximated by linear expressions. Mean, median and $\mathrm{CoV}$ of the observedto-predicted ratio are 1.02, 1.05 and 0.18, see Figure 5a. Again, the axial load ratio has the strongest influence also on this deformation capacity parameter. The beneficial effect of transverse reinforcement through the confinement effect on concrete in compression is demonstrated by the inclusion of the mechanical transverse reinforcement ratio. The inclusion of the "fixedend-rotation coefficient" demonstrates the possibility of taking into account the higher deformability due to this deformation mechanism through the proposed coefficient. As for $\theta_{\max }$, the minimum value between $1_{\mathrm{o}} / \mathrm{d}_{\mathrm{b}}$ and 50 was assumed as predictive parameter. Note that, different from the usual approach based on correction coefficients [18][19], which are calibrated a posteriori, in this case a unique expression is derived for elements with continuous and lap-spliced longitudinal reinforcement.

Another regression analysis is performed excluding the "fixed-end-rotation coefficient", because in some situations the anchorage length $l_{\text {ba }}$ cannot be easily determined, as for continuous longitudinal reinforcement passing through beam-column joints. The resulting expression includes, again, the axial load ratio, the mechanical transverse reinforcement ratio and the splice length-to-longitudinal bar diameter ratio, and, furthermore, the shear span-to-depth ratio, positively correlated to $\theta_{\text {ult, }}$, see Eq. 4. Mean, median and CoV of the observed-to-predicted ratio are 1.00, 1.00 and 0.20, see Figure 5b.

$$
\begin{gathered}
\theta_{u l t}=0.055 \cdot 0.034^{v} \cdot \omega_{s w}{ }^{0.15} \cdot\left(1+0.32 \cdot l_{b a} d_{b} / d \sqrt{f_{c}}\right) \cdot\left(0.70+0.30 \cdot \min \left(l_{o} / d_{b}, 50\right) / 50\right) \\
\theta_{u l t}=0.071 \cdot 0.039^{v} \cdot \omega_{s w}{ }^{0.18} \cdot\left(1+0.20 \cdot L_{s} / d\right) \cdot\left(0.75+0.25 \cdot \min \left(l_{o} / d_{b}, 50\right) / 50\right)
\end{gathered}
$$




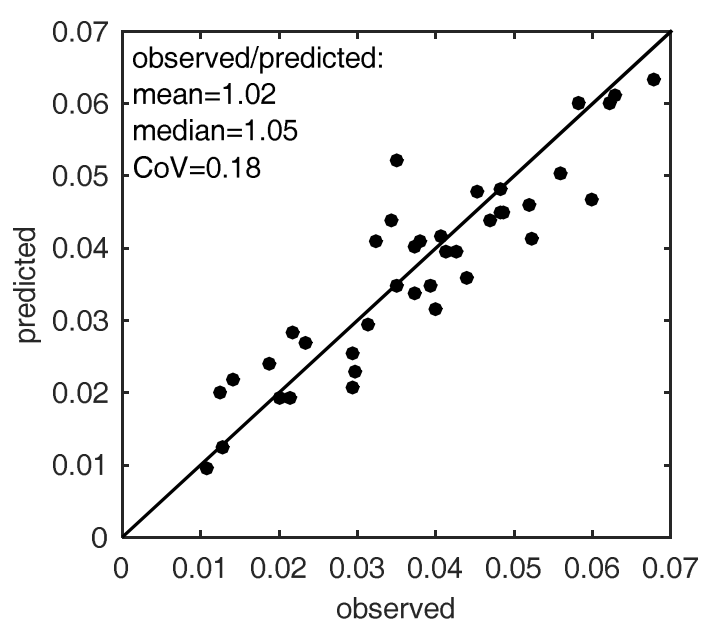

(a)

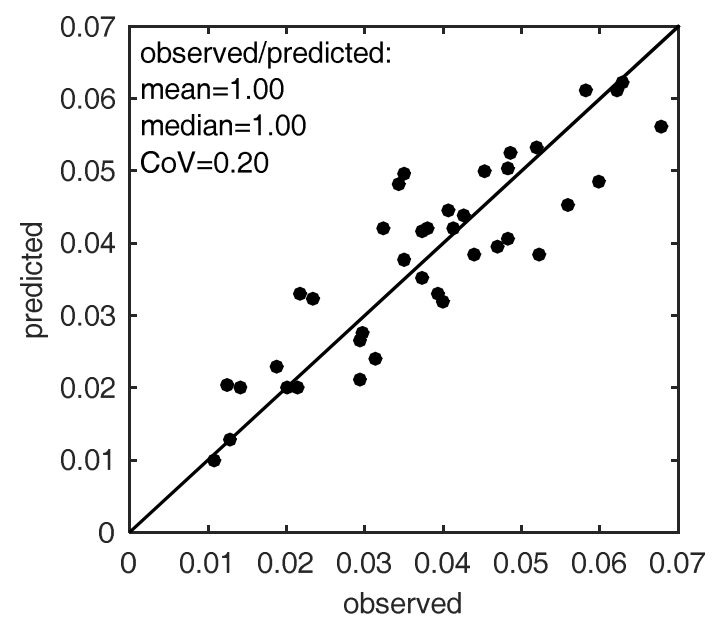

(b)

Figure 5: observed vs predicted $\theta_{\text {ult }}$ (Eq. 3 (a), Eq. 4 (b))

The obtained expressions can be compared with provisions by literature and codes for chord rotation at "ultimate". Formulations provided by the following references are considered: Eurocode 8 [18][19], without ("EC8") and with ("EC8c") correction coefficients accounting for the lack of seismic detailing and the presence of plain bars ("c.c."); Eurocode 8 with c.c. proposed by Verderame et al. [23] ("V\&al"); Eurocode 8 with c.c. proposed by Melo et al. [24] ("M\&al"); Biskinis and Fardis [2], without ("B\&F") and with ("B\&Fc"); c.c.; Zhu et al. [17], including the predicted Failure Mode ("FMz", "Z\&al"); ASCE/SEI 41-13 [21], including the predicted Failure Mode and Condition ("FMA", "Cond.", "ASCE"); Ghannoum [3], including the predicted Failure Mode $\left(\mathrm{FM}_{\mathrm{G}}, \mathrm{G}\right)$. In Table 3, these provisions are compared with the predictions of Eq. 3 and Eq. 4 proposed herein, and, of course, with observed values (" $\theta_{\text {ult,obs"). }}$ Finally, mean, median and $\mathrm{CoV}$ of the observed-to-predicted ratio are reported, for all columns ("all"), and separately for columns with continuous ("c.") and lap-spliced ("l.s.") longitudinal reinforcement, too.

The Equations proposed herein show the highest predictive capacity, and similar statistics of observed-to-predicted for "c." and "l.s." columns. The comparison with uncorrected EC8 provisions highlights that only for "l.s." columns a correction should be applied; however, the c.c. proposed by code lead to a significant underestimation of deformation capacity, both for "c." and "l.s." columns. Similar trends are observed for the update proposal by Fardis and coworkers [2]. The c.c. proposed by Verderame et al. [23] and Melo et al. [24] lead to a significantly better agreement, although quite conservative for "l.s." columns in the former case, and slightly non-conservative for "c." columns and conservative for "1.s." columns in the latter case. ASCE provisions [21] appear very conservative, but a direct comparison is not possible, since these provisions are calibrated to satisfy target failure probabilities rather than to predict the expected values, and, secondarily, because the significant underestimation of the effectiveness of end-hooked anchorages of plain longitudinal bars leads to unrealistic IS and/or ID failure modes [25][47][48]. The corresponding update proposal by Ghannoum [3], aimed at predicting median deformation capacity values, is, as expected, less (but still) conservative. 
Gerardo M. Verderame and Paolo Ricci

\begin{tabular}{|c|c|c|c|c|c|c|c|c|c|c|c|c|c|c|c|c|}
\hline$\#$ & $\begin{array}{l}\theta_{\text {ult,obs }} \\
{[\mathrm{rad}]} \\
\end{array}$ & $\begin{array}{l}\text { Eq. 3 } \\
{[\mathrm{rad}]} \\
\end{array}$ & $\begin{array}{c}\text { Eq.4 } \\
{[\mathrm{rad}]}\end{array}$ & $\begin{array}{c}\text { EC8 } \\
{[\mathrm{rad}]}\end{array}$ & $\begin{array}{l}\text { EC8c } \\
{[\mathrm{rad}]} \\
\end{array}$ & $\begin{array}{l}\text { V\&al } \\
\text { [rad] }\end{array}$ & $\begin{array}{c}\text { M\&al } \\
{[\mathrm{rad}]}\end{array}$ & $\begin{array}{l}\mathbf{B \& F} \\
\text { [rad] }\end{array}$ & $\begin{array}{c}\text { B\&Fc } \\
{[\mathrm{rad}]}\end{array}$ & $\mathbf{F M}_{\mathbf{z}}{ }^{*}$ & $\begin{array}{l}\text { Z\&al } \\
\text { [rad] }\end{array}$ & $\mathbf{F M}_{\mathbf{A}}^{\dagger}$ & Cond. & $\begin{array}{c}\text { ASCE } \\
{[\mathrm{rad}]}\end{array}$ & $\mathbf{F M}_{\mathbf{G}^{\dagger}}^{\frac{\hbar}{\xi}}$ & $\begin{array}{c}\mathbf{G} \\
{[\mathrm{rad}]}\end{array}$ \\
\hline 1 & 0.062 & 0.060 & 0.061 & 0.051 & 0.035 & 0.047 & 0.051 & 0.050 & 0.040 & $\mathrm{~F}$ & 0.037 & $\mathrm{~F}$ & ii & 0.028 & F-FS-S & 0.040 \\
\hline 2 & 0.058 & 0.060 & 0.061 & 0.051 & 0.035 & 0.047 & 0.051 & 0.050 & 0.040 & F & 0.037 & F & ii & 0.028 & F-FS-S & 0.040 \\
\hline 3 & 0.063 & 0.061 & 0.062 & 0.051 & 0.041 & 0.050 & 0.059 & 0.050 & 0.040 & F & 0.037 & $\mathrm{~F}$ & ii & 0.028 & F-FS-S & 0.040 \\
\hline 4 & 0.037 & 0.040 & 0.042 & 0.044 & 0.030 & 0.042 & 0.035 & 0.044 & 0.035 & F & 0.029 & F & ii & 0.025 & F-FS-S & 0.034 \\
\hline 5 & 0.038 & 0.041 & 0.042 & 0.044 & 0.035 & 0.045 & 0.041 & 0.044 & 0.035 & $\mathrm{~F}$ & 0.029 & $\mathrm{~F}$ & ii & 0.025 & F-FS-S & 0.034 \\
\hline 6 & 0.032 & 0.041 & 0.042 & 0.044 & 0.035 & 0.045 & 0.041 & 0.044 & 0.035 & F & 0.029 & F & ii & 0.025 & F-FS-S & 0.034 \\
\hline 7 & 0.056 & 0.050 & 0.045 & 0.038 & 0.030 & 0.038 & 0.046 & 0.037 & 0.029 & F & 0.026 & $\mathrm{~F}^{*}$ & ii & 0.022 & F-FS-S & 0.033 \\
\hline 8 & 0.068 & 0.063 & 0.056 & 0.045 & 0.036 & 0.044 & 0.060 & 0.044 & 0.035 & S & 0.058 & $\mathrm{~F}^{*}$ & ii & 0.021 & F-FS-S & 0.036 \\
\hline 9 & - & - & - & 0.032 & 0.026 & 0.030 & 0.042 & 0.032 & 0.025 & F & 0.044 & $\mathrm{~F}$ & ii & 0.022 & F-FS-S & 0.033 \\
\hline 10 & 0.052 & 0.041 & 0.038 & 0.039 & 0.031 & 0.039 & 0.044 & 0.039 & 0.031 & S & 0.040 & $\mathrm{~F}^{*}$ & ii & 0.019 & F-FS-S & 0.024 \\
\hline 11 & 0.048 & 0.045 & 0.041 & 0.040 & 0.032 & 0.040 & 0.047 & 0.039 & 0.031 & S & 0.055 & $\mathrm{~F}^{*}$ & ii & 0.019 & F-FS-S & 0.030 \\
\hline 12 & 0.019 & 0.024 & 0.023 & 0.038 & 0.030 & 0.039 & 0.022 & 0.037 & 0.030 & F & - & $\mathrm{F}^{*}$ & ii & 0.016 & F-FS-S & 0.020 \\
\hline 13 & 0.022 & 0.019 & 0.020 & 0.040 & 0.015 & 0.012 & - & 0.040 & 0.016 & F & - & IS & iv & 0.007 & IS & 0.032 \\
\hline 14 & 0.013 & 0.020 & 0.021 & 0.040 & 0.020 & 0.021 & - & 0.039 & 0.022 & $\mathrm{~F}$ & - & $\mathrm{F}^{*}$ & ii & 0.017 & F-FS-S & 0.022 \\
\hline 15 & 0.011 & 0.010 & 0.010 & 0.030 & 0.011 & 0.009 & - & 0.030 & 0.012 & F & - & IS & iv & 0.005 & IS & 0.030 \\
\hline 16 & 0.013 & 0.013 & 0.013 & 0.033 & 0.017 & 0.016 & - & 0.032 & 0.018 & F & - & $\mathrm{F}^{*}$ & ii & 0.012 & F-FS-S & 0.016 \\
\hline 17 & 0.037 & 0.034 & 0.035 & 0.044 & 0.035 & 0.048 & 0.037 & 0.044 & 0.034 & F & - & $\mathrm{F}^{*}$ & ii & 0.021 & F-FS-S & 0.027 \\
\hline 18 & 0.060 & 0.047 & 0.048 & 0.050 & 0.040 & 0.053 & 0.049 & 0.049 & 0.039 & F & 0.006 & $\mathrm{~F}^{*}$ & ii & 0.024 & F-FS-S & 0.032 \\
\hline 19 & 0.014 & 0.022 & 0.020 & 0.024 & 0.019 & 0.028 & 0.033 & 0.024 & 0.019 & F & 0.009 & $\mathrm{~F}^{*}$ & ii & 0.013 & F-FS-S & 0.018 \\
\hline 20 & 0.035 & 0.052 & 0.050 & 0.052 & 0.035 & 0.044 & 0.048 & 0.051 & 0.040 & $S$ & 0.062 & $\mathrm{~F}^{*}$ & ii & 0.022 & F-FS-S & 0.036 \\
\hline 21 & 0.029 & 0.021 & 0.021 & 0.038 & 0.026 & 0.034 & 0.019 & 0.038 & 0.030 & S & 0.054 & $\mathrm{~F}^{*}$ & ii & 0.016 & F-FS-S & 0.023 \\
\hline 22 & 0.031 & 0.030 & 0.024 & 0.033 & 0.022 & 0.031 & 0.032 & 0.032 & 0.025 & S & 0.054 & $\mathrm{~F}^{*}$ & ii & 0.015 & F-FS-S & 0.023 \\
\hline 23 & 0.044 & 0.036 & 0.038 & 0.038 & 0.030 & 0.039 & 0.046 & 0.038 & 0.030 & F & 0.025 & $\mathrm{~F}^{*}$ & ii & 0.023 & F-FS-S & 0.030 \\
\hline 24 & 0.047 & 0.044 & 0.040 & 0.040 & 0.032 & 0.040 & 0.051 & 0.039 & 0.031 & F & 0.009 & ID & iv & 0.004 & ID & 0.029 \\
\hline 25 & 0.039 & 0.035 & 0.033 & 0.040 & 0.017 & 0.016 & - & 0.040 & 0.019 & F & 0.009 & IS/ID & iv & 0.004 & IS/ID & 0.029 \\
\hline 26 & 0.029 & 0.025 & 0.027 & 0.029 & 0.023 & 0.033 & 0.032 & 0.029 & 0.023 & F & 0.011 & $\mathrm{~F}^{*}$ & ii & 0.017 & F-FS-S & 0.024 \\
\hline 27 & 0.040 & 0.032 & 0.032 & 0.035 & 0.028 & 0.038 & 0.032 & 0.034 & 0.027 & F & 0.021 & $\mathrm{~F}^{*}$ & ii & 0.021 & F-FS-S & 0.027 \\
\hline 28 & 0.020 & 0.019 & 0.020 & 0.024 & 0.019 & 0.027 & 0.027 & 0.024 & 0.019 & F & 0.039 & $\mathrm{~F}^{*}$ & ii & 0.017 & F-FS-S & 0.021 \\
\hline 29 & - & - & - & - & - & - & - & - & - & - & - & - & - & 0.024 & - & - \\
\hline 30 & - & - & - & - & - & - & - & - & - & - & - & - & - & 0.024 & - & - \\
\hline 31 & 0.030 & 0.023 & 0.028 & 0.029 & 0.023 & 0.032 & 0.033 & 0.029 & 0.023 & F & 0.015 & $\mathrm{~F}^{*}$ & ii & 0.017 & F-FS-S & 0.026 \\
\hline 32 & - & - & - & - & - & - & - & - & - & - & - & - & - & 0.024 & - & - \\
\hline 33 & - & - & - & - & - & - & - & - & - & - & - & - & - & 0.024 & - & - \\
\hline 34 & 0.052 & 0.046 & 0.053 & 0.036 & 0.029 & 0.038 & 0.049 & 0.036 & 0.029 & $\mathrm{~F}$ & 0.030 & $\mathrm{~F}^{*}$ & ii & 0.024 & F-FS-S & 0.036 \\
\hline 35 & 0.049 & 0.045 & 0.053 & 0.037 & 0.029 & 0.039 & 0.048 & 0.036 & 0.029 & F & 0.029 & $\mathrm{~F}^{*}$ & ii & 0.024 & F-FS-S & 0.036 \\
\hline 36 & 0.034 & 0.044 & 0.048 & 0.047 & 0.038 & 0.049 & 0.053 & 0.046 & 0.037 & S & 0.062 & $\mathrm{~F}^{*}$ & ii & 0.022 & F-FS-S & 0.035 \\
\hline 37 & 0.045 & 0.048 & 0.050 & 0.045 & 0.036 & 0.048 & 0.056 & 0.044 & 0.035 & S & 0.061 & $\mathrm{~F}^{*}$ & ii & 0.022 & F-FS-S & 0.035 \\
\hline 38 & 0.043 & 0.039 & 0.044 & 0.047 & 0.027 & 0.029 & - & 0.046 & 0.029 & S & 0.062 & IS & iv & 0.007 & IS & 0.032 \\
\hline 39 & 0.048 & 0.048 & 0.050 & 0.045 & 0.036 & 0.048 & 0.056 & 0.044 & 0.035 & $\mathrm{~S}$ & 0.061 & $\mathrm{~F}^{*}$ & ii & 0.023 & F-FS-S & 0.035 \\
\hline 40 & 0.041 & 0.042 & 0.045 & 0.045 & 0.026 & 0.029 & - & 0.045 & 0.028 & $S$ & 0.061 & IS & iv & 0.009 & IS & 0.030 \\
\hline 41 & 0.041 & 0.039 & 0.042 & 0.037 & 0.029 & 0.038 & 0.044 & 0.036 & 0.029 & $\mathrm{~S}$ & 0.044 & $\mathrm{~F}^{*}$ & ii & 0.020 & F-FS-S & 0.031 \\
\hline 42 & 0.035 & 0.035 & 0.038 & 0.035 & 0.028 & 0.035 & 0.042 & 0.034 & 0.027 & S & 0.034 & $\mathrm{~F}^{*}$ & ii & 0.019 & F-FS-S & 0.028 \\
\hline 43 & 0.024 & 0.027 & 0.032 & 0.039 & 0.031 & 0.039 & 0.035 & 0.039 & 0.031 & S & 0.034 & FS & ii & 0.019 & F-FS-S & 0.019 \\
\hline 44 & 0.022 & 0.028 & 0.033 & 0.038 & 0.030 & 0.038 & 0.038 & 0.038 & 0.030 & $\mathrm{~S}$ & 0.034 & FS & ii & 0.019 & F-FS-S & 0.019 \\
\hline \multirow{3}{*}{ సี } & mean & 1.02 & 1.00 & 0.94 & 1.30 & 1.06 & 0.96 & 0.95 & 1.28 & & 1.67 & & & 2.57 & & 1.27 \\
\hline & median & 1.05 & 1.00 & 0.98 & 1.35 & 1.01 & 0.94 & 0.99 & 1.31 & & 1.28 & & & 2.02 & & 1.32 \\
\hline & $\mathrm{CoV}$ & 0.18 & 0.20 & 0.33 & 0.30 & 0.36 & 0.24 & 0.33 & 0.30 & & 1.03 & & & 0.93 & & 0.29 \\
\hline \multirow{3}{*}{ ن } & mean & 1.03 & 1.00 & 1.03 & 1.28 & 0.99 & 0.92 & 1.04 & 1.31 & & 1.81 & & & 2.31 & & 1.36 \\
\hline & median & 1.06 & 0.99 & 1.05 & 1.31 & 1.00 & 0.92 & 1.06 & 1.34 & & 1.30 & & & 1.93 & & 1.34 \\
\hline & $\mathrm{CoV}$ & 0.17 & 0.19 & 0.28 & 0.28 & 0.30 & 0.22 & 0.28 & 0.28 & & 1.04 & & & 0.95 & & 0.24 \\
\hline \multirow{3}{*}{$\dot{\leftrightarrow}$} & mean & 1.01 & 1.01 & 0.77 & 1.34 & 1.21 & 1.11 & 0.78 & 1.21 & & 1.32 & & & 3.07 & & 1.09 \\
\hline & median & 1.04 & 1.00 & 0.84 & 1.41 & 1.19 & 1.10 & 0.85 & 1.22 & & 0.69 & & & 2.10 & & 1.29 \\
\hline & $\mathrm{CoV}$ & 0.20 & 0.21 & 0.38 & 0.35 & 0.41 & 0.25 & 0.38 & 0.34 & & 0.92 & & & 0.88 & & 0.35 \\
\hline
\end{tabular}

$*: \mathrm{F}=$ flexure; $\mathrm{S}=$ flexure-shear or shear.

$\dagger: F=$ flexure with further confidence; $F^{*}=$ flexure without further confidence; FS = flexure-shear; ID: inadequate development; IS: inadequate splicing.

†:F-FS-S = flexure or flexure-shear or shear; ID: inadequate development; IS: inadequate splicing.

Table 3: Comparison between observed and predicted chord rotation at "ultimate"

\section{Chord rotation at zero resistance}

For some tests, very high, unrealistic values of $\theta_{0}$ were obtained, due to very low post-peak negative slope, unrealistically high values of $\theta_{0}$ were obtained. Hence, a judgment-based value of $0.15 \mathrm{rad}$ was assumed as upper bound for this parameter.

The regression obtained for $\theta_{0}$ includes the axial load ratio and the geometrical transverse reinforcement ratio, see Eq. 5. Mean, median and $\mathrm{CoV}$ of the observed-to-predicted ratio, with the assumed upper bound on observed and predicted values, ratio are $0.99,0.93$ and 0.37 , see Figure 6.

$$
\theta_{0}=\min \left(0.098 \cdot 0.015^{v} \cdot 58^{\left(\rho_{w} \cdot 100\right)} ; 0.15\right)
$$




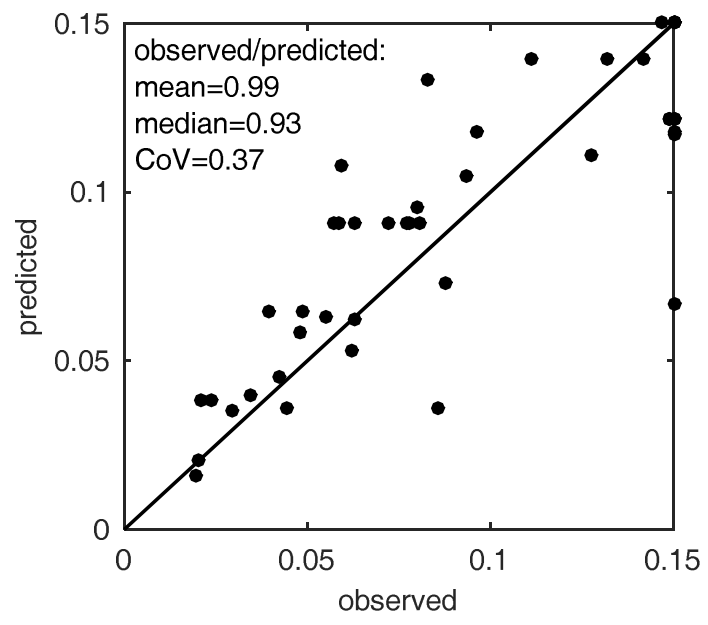

Figure 6: observed vs predicted $\theta_{0}$ (Eq. 5)

\section{Softening stiffness toward zero resistance}

Due to the strict dependency between $\theta_{0}$ and $\mathrm{K}_{0}$, the adoption of a (lower) bound for this parameter is considered. To this aim, $K_{0}$ is reported versus $\theta_{0}$ (see Figure 7 ): assuming a lower bound on $\mathrm{K}_{0}$ equal to $700 \mathrm{kNm} / \mathrm{rad}$, almost all (except two) tests with $\theta_{0} \leq 0.15$ show a value of $\mathrm{K}_{0}$ above this bound, while all the tests with $\theta_{0}>0.15$ show a value of $\mathrm{K}_{0}$ below this bound.

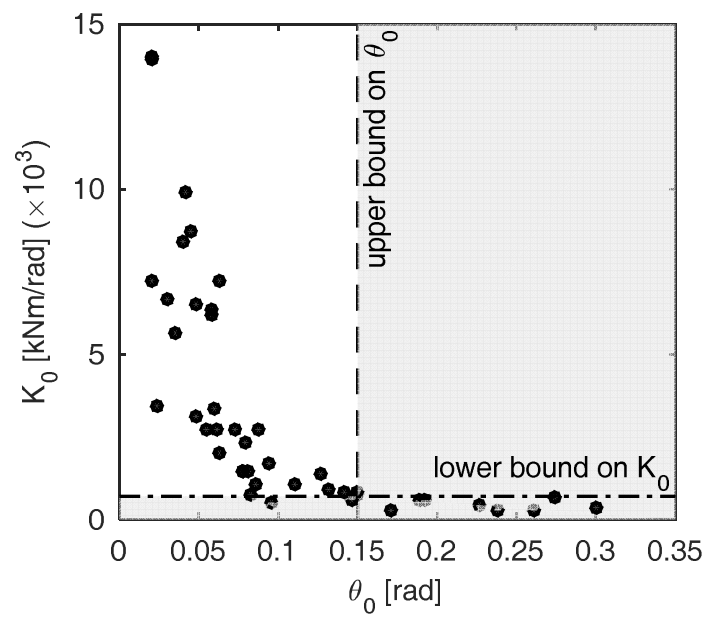

Figure 7: observed $\theta_{0}$ vs observed $\mathrm{K}_{0}$ and corresponding assumed bounds

The regression obtained for $\mathrm{K}_{0}$ includes the same parameters of the regression obtained for $\theta_{0}$, see Eq. 6. Mean, median and $\mathrm{CoV}$ of the observed-to-predicted ratio, with the assumed lower bound on observed and predicted values, ratio are 1.27, 1.00 and 0.62, see Figure 8.

$$
K_{0}=\max \left(30 \cdot 327^{v} \cdot\left(\rho_{w} \cdot 100\right)^{-1.69} ; 700\right)
$$




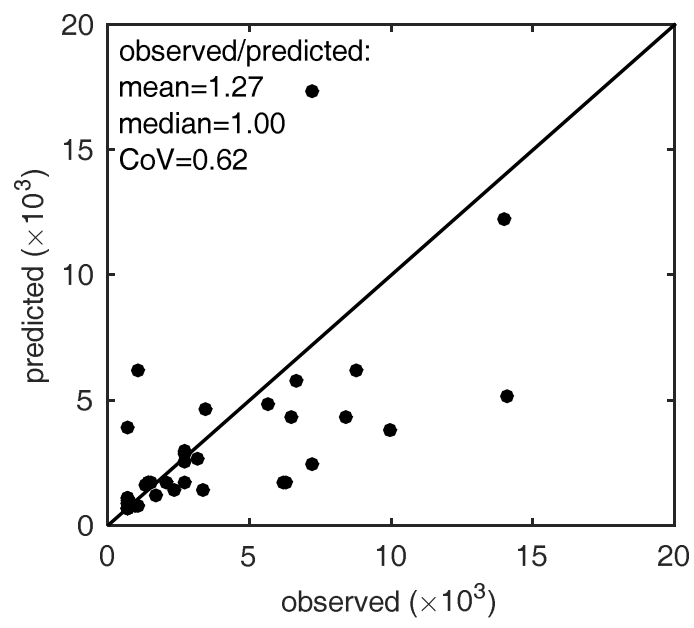

Figure 8: observed vs predicted $\mathrm{K}_{0}$ (Eq. 6)

\section{CONCLUSIONS}

An empirical macro-model for the prediction of inelastic response of flexure-controlled RC columns with plain bars was proposed. To this aim, a database of cyclic tests was collected, parameters identifying the characteristic point of the response envelope were identified, and a regression analysis was performed in order to derive empirical formulations predicting these parameters. The proposed equations allow modeling the inelastic response up to complete collapse (zero-resistance condition). A comparison was carried out between proposed equations for deformability at yielding (effective stiffness) and chord rotation at "ultimate" (20\% strength drop) and proposals from literature and codes, highlighting, in the latter case, a general conservatism.

The proposed formulations can be used both for performance-based deformation capacity assessment and for nonlinear modeling, thus representing a useful tool for seismic analysis of existing $\mathrm{RC}$ frames with plain reinforcing bars, properly accounting for the specific response characteristics of this kind of members.

\section{ACKNOWLEDGEMENTS}

This work was developed under the financial support of ReLUIS-DPC 2014-2018. This support is gratefully acknowledged.

\section{REFERENCES}

[1] Elwood K.J., Matamoros A.B., Wallace J.W., Lehman D.E., Heintz J.A., Mitchell A.D., Moore M.A., Valley M.T., Lowes L.N., Comartin C.D., Moehle J.P., 2007. Update to ASCE/SEI 41 concrete provisions. Earthquake Spectra, 23(3), 493-523. 1

[2] Biskinis D.E., Fardis M.N., 2010b. Flexure-controlled ultimate deformations of members with continuous or lap-spliced bars. Structural Concrete, 11(2), 93-108. 2

[3] Ghannoum W.M., 2017. Re-evaluation of modeling parameters and acceptance criteria for non-ductile and splice-deficient concrete columns. 16th World Conference on Earthquake Engineering, Santiago, Chile, January 9-13. Paper No. 1010. 3 
[4] Verderame G.M., Ricci P., De Carlo G., Manfredi G., 2009a. Cyclic bond behaviour of plain bars. Part I: Experimental investigation. Construction and Building Materials, 23(12), 3499-3511.

[5] Verderame G.M., De Carlo G., Ricci P., Fabbrocino G., 2009b. Cyclic bond behaviour of plain bars. Part II: Analytical investigation. Construction and Building Materials, 23(12), 3512-3522.

[6] Verderame G.M., Fabbrocino G., Manfredi G., 2008a. Seismic response of RC columns with smooth reinforcement. Part I: Monotonic tests. Engineering Structures, 30(9), 22772288 .

[7] Verderame G.M., Fabbrocino G., Manfredi G., 2008b. Seismic response of RC columns with smooth reinforcement. Part II: Cyclic tests. Engineering Structures, 30(9), 22892300. 24

[8] Haselton C.B., Liel A.B., Taylor-Lange S., Deierlein G.G., 2008. Beam-column element model calibrated for predicting flexural response leading to global collapse of RC frame buildings. PEER Report 2007/03. Pacific Earthquake Engineering Research Center, University of California, Berkeley, CA, USA. 4

[9] Ibarra L.F., Medina R.A., Krawinkler H., 2005. Hysteretic models that incorporate strength and stiffness deterioration. Earthquake Engineering and Structural Dynamics, 34(12), 1489-1511. 5

[10] Panagiotakos T.B., Fardis M.N., 2001. Deformation of reinforced concrete members at yielding and ultimate. ACI Structural Journal, 98(2), 135-148. 6

[11] Biskinis D.E., Fardis M.N., 2010a. Deformations at flexural yielding of members with continuous or lap-spliced bars. Structural Concrete, 11(3), 127-138. 7

[12] Elwood K.J., Moehle J.P., 2005a. Axial capacity model for shear-damaged columns. ACI Structural Journal, 102(4), 578-587. 8

[13] Elwood K.J., Moehle J.P., 2005b. Drift capacity of reinforced concrete columns with light transverse reinforcement. Earthquake Spectra, 21(1), 71-89. 9

[14] Elwood K.J., 2004. Modelling failures in existing reinforced concrete columns. Canadian Journal of Civil Engineering, 31(5), 846-859. 10

[15] McKenna F., Fenves G.L., Scott M.H., 2004. OpenSees: Open System for Earthquake Engineering Simulation. Pacific Earthquake Engineering Research Center. University of California, Berkeley, CA, USA. http://opensees.berkeley.edu 11

[16] Aslani H., Miranda E., 2005. Probabilistic earthquake loss estimation and loss disaggregation in buildings. Report No. 157. The John A. Blume Earthquake Engineering Center, Department of Civil and Environmental Engineering, Stanford University, Stanford, CA, USA. 12

[17] Zhu L., Elwood K.J., Haukaas T., 2007. Classification and seismic safety evaluation of existing reinforced concrete columns. ASCE Journal of Structural Engineering, 133(9), 1316-1330. 13

[18] CEN, 2005. European standard EN1998-3. Eurocode 8: Design provisions for earthquake resistance of structures. Part 3: Assessment and retrofitting of buildings. Comite Européen de Normalisation, Brussels. 14 
[19] CEN, 2009. Corrigenda to EN 1998-3. Document CEN/TC250/SC8/N437A. Comité Européen de Normalisation, Brussels. 15

[20] Panagiotakos T.B., Kosmopoulos A.J., Fardis M.N., 2002. Displacement-based seismic assessment and retrofit of reinforced concrete buildings. 1st fib congress, Osaka, Japan, October 13-19. Pp. 269-278. 16

[21] ASCE, 2013. ASCE/SEI 41-13. Seismic evaluation and retrofit of existing buildings. American Society of Civil Engineers, Reston, VA, USA. 17

[22] Ghannoum W.M., Matamoros A.B., 2014. Nonlinear modeling parameters and acceptance criteria for concrete columns. ACI Special Publication, 297, 1-24. 18

[23] Verderame G.M., Ricci P., Manfredi G., Cosenza E., 2010. Ultimate chord rotation of RC columns with smooth bars: some considerations about EC8 prescriptions. Bulletin of Earthquake Engineering, 8(6), 1351-1373. 18

[24] Melo J., Varum H., Rossetto T., 2015. Experimental cyclic behaviour of RC columns with plain bars and proposal for Eurocode 8 formula improvement. Engineering Structures, 88, 22-36. 19

[25] Ricci P., Verderame G.M., Manfredi G., 2013. ASCE/SEI 41 provisions on deformation capacity of older-type reinforced concrete columns with plain bars. ASCE Journal of Structural Engineering, 139(12). 20

[26] Berry M., Parrish M., Eberhard M., 2004. PEER Structural Performance Database: User's Manual, Version 1.0. Pacific Earthquake Engineering Research Center, University of California, Berkeley, CA, USA. 21

[27] Elwood K.J., Eberhard M., 2009. Effective stiffness of reinforced concrete columns. ACI Structural Journal, 106(4), 476-484. 22

[28] Bousias S., Spathis A.L., Fardis M.N., 2007. Seismic retrofitting of columns with lap spliced smooth bars through FRP or concrete jackets. Journal of Earthquake Engineering, 11(5), 653-674. 23

[29] Di Ludovico M., Verderame G.M., Prota A., Manfredi G., Cosenza E., 2014. Cyclic behavior of nonconforming full-scale RC columns. ASCE Journal of Structural Engineering, $140(5)$

[30] Di Ludovico M., 2017. Personal communication. 26

[31] Bournas D.A., Lontou P.V., Papanicolaou C.G., Triantafillou T.C., 2007. Textile-Reinforced Mortar versus Fiber-Reinforced Polymer confinement in reinforced concrete columns. ACI Structural Journal, 104(6), 740-748.

[32] Bournas D.A., Triantafillou T.C., 2009. Flexural strengthening of reinforced concrete columns with Near-Surface-Mounted FRP or stainless steel. ACI Structural Journal, 106(4), 495-505. 28

[33] Ilki A., Tezcan A., Koc V., Kumbasar N., 2004. Seismic retrofit of non-ductile rectangular reinforced concrete columns by CFRP jacketing. 13th World Conference on Earthquake Engineering, Vancouver, B.C., Canada, August 1-6. Paper No. 2236.29

[34] Faella C., Napoli A., Realfonzo R., 2008. Cyclic flexural behavior of FRP-confined concrete columns under high axial loading. Atti del convegno ReLUIS "Valutazione e 
riduzione della vulnerabilità sismica di edifici esistenti in c.a.”, Rome, Italy, May 29-30. Pp. 510-520. 30

[35] Marefat M.S., Arani K.K., Hassanzadeh Shirazi S.M., Amrollahi-Biucky A., 2008. Seismic behavior and retrofit of concrete columns of old r.c. buildings reinforced with plain bars. In: Santini A., Moraci N. (editors). 2008 Seismic Engineering Conference Commemorating the 1908 Messina and Reggio Calabria Earthquake. AIP Conference Proceedings, 2008. ISBN 978-0-7354-0542-4. Volume 1020, pp. 1554-1562. doi: $10.1063 / 1.296378331$

[36] Arani K.K., Marefat M.S., Amrollahi-Biucky A., Khanmohammadi M., 2010. Experimental seismic evaluation of old concrete columns reinforced by plain bars. The Structural Design of Tall and Special Buildings, 22(3), 267-290. 32

[37] Ozcan O., Binici B., Ozcebe G., 2008. Improving seismic performance of deficient reinforced concrete columns using carbon fiber-reinforced polymers. Engineering Structures, 30(6), 1632-1646.

[38] Ozcan O., 2009. Improving ductility and shear capacity of reinforced concrete columns with carbon fiber reinforced polymer. PhD Thesis. Middle East Technical University, Ankara, Turkey. 33

[39] Ozcan O., Binici B., Ozcebe G., 2010. Seismic strengthening of rectangular reinforced concrete columns using fiber reinforced polymers. Engineering Structures, 32(4), 964973.

[40] Acun B., Sucuoglu H., 2010. Performance of reinforced concrete columns designed for flexure under severe displacement cycles. ACI Structural Journal, 107(3), 364-371. 34

[41] Acun B., Sucuoglu H., 2012a. Energy dissipation capacity of reinforced concrete columns under cyclic displacements. ACI Structural Journal, 109(4), 531-540.

[42] Acun B., Sucuoglu H., 2012b. Energy-based hysteresis model for flexural response of reinforced concrete columns. ACI Structural Journal, 109(4), 541-550.

[43] Rodriguez M., Park R., 1994. Seismic load tests of reinforced concrete columns strengthened by jacketing. ACI Structural Journal, 91(2), 150-159. 36

[44] Draper N.R., Smith H., 1998. Applied regression analysis. John Wiley \& Sons, 3rd edition. 37

[45] Mander J.B., Priestley M.J.N., Park R., 1988. Theoretical stress-strain model for confined concrete. ASCE Journal of Structural Engineering, 114(8), 1804-1826. 37

[46] NZS, 2006. NZS 3101:2006. Concrete Structures Standard. Standards New Zealand, Wellington, New Zealand. 38

[47] Fabbrocino G., Verderame G.M., Manfredi G., Cosenza E., 2004. Structural models of critical regions in old-type r.c. frames with smooth rebars. Engineering Structures, 26(14), 2137-2148.

[48] Fabbrocino G., Verderame G.M., Manfredi G., 2005. Experimental behaviour of anchored smooth rebars in old type reinforced concrete buildings. Engineering Structures, 27(10), 1575-1585. 